This article was published in School Leadership and Management

Vol. 30, No. 5, November 2010, pps. 469 -486

\title{
The role of school leadership in the implementation of the Transition Year Programme in Ireland
}

\author{
Gerry Jeffers \\ Education Department \\ National University of Ireland, Maynooth, Ireland
}

gerard.jeffers@nuim.ie 


\title{
The role of school leadership in the implementation of the Transition Year Programme in Ireland
}

\author{
Gerry Jeffers
}

Introducing an educational innovation into any school context involves some challenge to existing practices. Transition Year is an innovative, optional, one-year programme taken by approximately half the 15-16-year age cohort in schools in the Republic of Ireland. Based on data from an extensive study of TY operating in six different schools, programme co-ordinators and school principals are identified as having key roles in the successful implementation of TY. However, exercising the collegiality both roles demand goes against established cultures of isolated individualism in Irish schools. Furthermore, maintaining TY's coherence and integrity in the face of threats from more established programmes offers particular challenges. For this innovation to be successful, active curriculum leadership by school principals is seen as crucial. The paper interrogates the evidence through the lens of the 2008 OECD study on school leadership and poses questions about the relevance and value of the OECD perspective.

Keywords: leadership; change; curriculum; Transition Year; Ireland; innovation Introduction

\section{Introduction}

The OECD study on Improving school leadership (Pont, Nusche, and Moorman 2008) signals 'the essential character of school leadership' as leadership for learning.

Furthermore, it identifies 'redefining school leadership responsibilities for improved student learning' as a key 'policy lever' which can improve school leadership practice (32). It proceeds to highlight four major domains of responsibility as key in order to improve student outcomes. These are:

- Supporting, evaluating and developing teacher quality.

- Goal setting, assessment and accountability.

- Strategic financial and human resource management.

- Collaborating with other schools.

This paper examines the practice of school leadership in relation to a major curriculum innovation in Ireland, the Transition Year (TY) programme, as an example of 'leadership for learning'. Initially, the paper sets out the key features of the TYprogramme. It then reports on a research project that examined attitudes to TY in schools, focusing specifically on the leadership dimensions of the study. The subsequent discussion is structured and illuminated through the lens of the OECD perspective with the dual purpose of interrogating the TY initiative and also testing the relevance and value of the OECD view of school leadership policy priorities.

\section{The Transition Year programme}

Transition Year (TY) is an optional, one-year, stand-alone, full-time programme offered by schools in the Republic of Ireland. It is taken by 15- to 16-year-olds on 
completion of the three-year Junior Certificate (JC) programme and prior to a twoyear Leaving Certificate (LC) programme.

TY has a strong focus on personal and social development and on education for active citizenship. The invitation to schools is to devise a broad, holistic educational experience that promotes maturity and greater responsibility in students for their own learning and decision-making (Ireland, Department of Education 1993, 3). Aims include increased social awareness and social competence with education through experience of adult and working life as a basis for personal development and maturity $(1993,4)^{1}$.

TY presents school leaders with particular opportunities and challenges. The freedom given to schools to design a TYprogramme suited to the specific needs of its students is a significant one. In a system that is highly centralised and dominated by the effects of the LC, a high stakes public examination, TY represents a more holistic, learningled, community orientated programme (Smyth, Byrne, and Hannan 2004; Jeffers 2007). This emphasis is in sharp contrast to the values associated with the LC, where points generated in the final examination determine access to third-level education. Respecting the integrity of TY as a coherent programme rather than a series of fragmented activities, especially in the shadow of the LC, is particularly challenging.

Policy decisions that included financial incentives and practical support for schools and teachers have led to a significant increase in participation since TY was mainstreamed in 1994. According to the Department of Education and Science: 'Transition Year, which has been one of the major innovations in Irish education, is an option which is now firmly embedded in the system' (Ireland, Department of Education and Science 2004, 13).

\section{Purpose}

This paper focuses on the opportunities and challenges that school leaders face in implementing TY in individual schools. Based on data from a study of attitudes to TY in six different schools, the intention is to identify good leadership practice regarding the implementation of TY and to report on opportunities not grasped. Furthermore, leadership of the TY project is viewed through the lens of the OECD 2008 study of school leadership in 22 countries and its recommendations, particularly for policy priorities. In so doing the relevance and value of that same lens will also be illuminated.

\section{Methodology and data sources}

\footnotetext{
${ }^{1}$ An introductory note to the Guidelines offers the following overview of TY: 'A Transition Year offers pupils a broad educational experience with a view to the attainment of increased maturity, before proceeding to further study and/or vocational preparation. It provides a bridge to help pupils make the transition from a highly-structured environment to one where they will take greater responsibility for their own learning and decision-making. Pupils will participate in learning strategies which are active and experiential and which help them to develop a range of transferable critical thinking and creative problem-solving skills. The Transition Year also provides an opportunity for pupils to reflect on and develop an awareness of the value of education and training in preparation for the ever-changing demands of the adult world of work and relationships' (Ireland, Department of Education 1993, 3).
} 
This paper derives mainly from a study of the operation of TY in six different schools (Jeffers 2007). The six schools covered a range of contexts as set out in Table 1. 
Table 1. Schools in the study.

School

Brief description

Ash School

Beech School

Chestnut School

Ash School is a voluntary secondary school for girls, founded by a religious order of sisters in the early nineteenth century. Ash School introduced TY in 1990, thus maintaining a six-year cycle. This compulsory programme is clearly structured into three 10-week blocks with a wide range of modules available. Both Principal and co-ordinator were unequivocal about the benefits of a compulsory TY for their students.

Beech School is a co-educational community college, designated 'disadvantaged'. Beech School sees its mission unequivocally as improving the life chances of its students, many of whom live in disadvantaged circumstances. The experience in Beech School points to a very direct correlation between taking part in TY and improved maturity, including more informed subject choices and improved motivation for LC. In turn, this improved motivation has led to increased levels of examination achievement and greater participation at thirdlevel. The emergence of positive role models from within Beech School is regarded as a leaven throughout the school, raising expectations all round.

Chestnut School is an all-boys voluntary secondary school in a suburban location. Each year a majority of students in Chestnut School opt for TY. The school has a strong tradition of high academic results and TY is seen by many students and teachers as enhancing this, not least by strengthening a platform for LC achievement. There is also a strong consensus that TY enhances boys' maturity.

Maple School

Maple School is a co-educational VEC school, located in a small town (population less than 2000) in the west of Ireland. Maple School is an example of a relatively small school offering an imaginative, engaging and effective optional TY progamme. There is extensive evidence that students, teachers and parents value highly what has been developed. A wise and enabling principal, a staff prepared to take risks and a very visionary co-ordinator have combined to develop a programme that appears to meet students' needs well. The Maple School community sees the positive publicity generated by TY activities as enhancing its standing within the wider local community. As a small school with poor physical facilities, building such a reputation has been a priority for the school overall. Thus, as in the other five schools, adapting and, in this case projecting, TY to fit with the school's thinking about itself, 'domesticating' it, is also evident. 
Table 1. (Continued ).

School

Brief description

Oak School Oak School is an all-girls school, designed 'disadvantaged', serving an established urban community. The decision in 1994 to offer TY was partly a pragmatic one in the face of a declining school population. Strong leadership, particularly a forceful co-ordinating team, appears to have enabled the school to develop a TY that makes a definite difference in the lives of the students who opt for it. Principal and co-ordinator both point to the staff team developing the school's specific programme by regular and frank evaluations, each year dropping 'the bits that didn't work'. Students themselves speak highly of their own personal and social development through the TY experience. Within classrooms, project work and a particular emphasis on active participatory approaches to learning appear to be especially effective and, when linked with the extra-classroom learning activities, contribute to a markedly different character of relationship.

Sycamore School Sycamore School is a community school in a rural location. Partly driven by fears of TY being seen as a 'doss year', Sycamore School put a strong academic emphasis in its optional TY programme from the start. The school would like to increase its intake into TY but senses strong resistance from students and parents. The co-ordinator believes that more boys in particular could benefit greatly from the personal and social development that TY facilitates. Dealing with a predominantly rural population, the Principal detects strong pragmatic concerns in the community concerning a six-year second-level cycle, especially the potential impact of an additional year on drop-out rates in the fifth and sixth years.

Both quantitative and qualitative methods were used in exploring the following research question:

- What are the attitudes of the critical actors - students, teachers, parents and school leaders - towards TY and how do these attitudes manifest themselves in the operation of TY at six distinct school sites?

This paper focuses primarily on the school leadership dimension of that study. Data gathering consisted of: 16 individual interviews with school principals and TY coordinators; 26 focus group interviews involving 111 students; two focus group interviews with 10 parents; an extensive teacher questionnaire completed by 113 teachers; and documentary evidence in the form of published and unpublished material from each of the six schools. While concentrating in this paper on the data from the 16 principals and co-ordinators, the insights regarding leadership from other stakeholders also offer valuable perspectives. Furthermore, the data is viewed through the author's particular lens, shaped by nine years' experience as a deputy principal in 
a school that developed a TY programme and five years as a member of a national support service for the implementation of TY.

\section{Development of the Transition Year programme}

Since the mid 1990s a majority of second-level schools in the Republic of Ireland have offered TY to their students. The pattern has been that most schools offer TYas an optional programme, thus creating an anomaly whereby some young people spend six years in the secondary cycle while others only spend five. The uptake rate is such that currently just over $75 \%$ of schools and more than $50 \%$ of the relevant students follow TY rather than beginning the two-year LC (established) or the LC Applied (LCA) immediately after the JC examination (see Table 2). between students and teachers in the Fourth, Fifth and Sixth years compared to that in the Junior Cycle. The opportunity to sample LC subjects during TY is seen by students, teachers and parents as leading to more informed choices of LC subjects.

Table 2. Uptake of TY programme in selected years 1993-2010.

Year

Number of schools offering TY
Number of students doing TY
Numbers doing TY as a percentage of numbers sitting previous year's JC examination

\begin{tabular}{lclc}
\hline $1993-1994$ & 163 & 8,499 & $13 \%$ \\
$1994-1995$ & 450 & 21,085 & $31.3 \%$ \\
$2000-2001$ & 498 & 23,727 & $36.7 \%$ \\
$2003-2004$ & 526 & 23,299 & $38.7 \%$ \\
$2006-2007$ & 524 & 27,090 & $46.7 \%$ \\
$2009-2010$ & 555 & 28,657 & $53 \%$
\end{tabular}

\section{Crucial choices for schools}

This situation has presented school leaders in particular with crucial decisions concerning the offering of TY and, subsequently for some, whether it should be compulsory or optional. In schools where TY remains contested, school leaders have to revisit this decision regularly. The evidence suggests that school leaders' own beliefs about the value of TY emerge as an important consideration. For example, the principal of Ash School was in no doubt about the value of the programme. That school embraced the TY emphasis on holistic development. The principal led from the front:

I believe that if Transition Year was an option in my school, honestly it wouldn't say much for Transition Year. If some students can go from 3rd to 5th year without losing out, does it mean that the others (those who do TY) just have a nice, cosy experience? . . . I see it (TY) as an essential part of their development. (Jeffers 2007, 144)

She added that every year a small number of students leave the school so as to fasttrack themselves onto an LC programme.

By contrast, the principal of Sycamore School adopted a pragmatic position in the face of ambiguous attitudes in the staffroom. The result was a skewing of TY towards particular students: 
There was a lot of feeling against it, that it was going to be a doss year ...We went down the line of making it as academic as possible in the sense that we would gear it to students who had high ambitions, who were young, and who weren't sure of their subject options or their career choices at fifteen years of age or sixteen; they would be encouraged to take the TY. (Jeffers 2007, 227)

A pragmatism relating to curriculum innovation also emerges from the principal of Chestnut School, an all-boys school, and indicates some of the perspectives that can emerge from consulting parents:

Some parents say that it (TY) is the worst thing that ever happened to their son, while others say it is wonderful, so you are left wondering at times. (Jeffers 2007, 187)

Two of the schools in the study were designated 'disadvantaged'2. In these schools, explaining the merits of TY to students and their parents - many of whom themselves have limited direct experience of senior cycle schooling - was seen as especially challenging, particularly at the outset. Both schools had introduced, developed and sustained a TYprogramme against considerable odds. A strong belief in TY on the part of the two principals appears as an important driving force in both situations, suggesting that decisions taken at school level can be significant in an individual school going against the grain of national patterns and trends. There are also signs of how parents' perceptions change and confidence in the programme alters over time.

For example, the principal of Oak School remarked:

I remember the information nights ... going back, maybe four or five years ago. You would get a lot of negative stuff coming from the floor about the fact that it is a 'doss year', that they would get out of the habit of studying, that they are spending an extra year in school which means that the way the parents put it, it is 'a year's money gone'. Now I haven't had that at all, for the last two years certainly.

\section{Shaping the Transition Year programme}

There is a strong tradition within Irish education of curriculum being centrally devised and highly prescriptive. TY, in contrast, offers schools extensive liberty. According to the guidelines:

Curriculum content is a matter for selection and adaptation by the individual school having regard to these guidelines, the requirements of pupils and the views of parents. In

establishing its curriculum, the school should take into consideration the possibilities offered by employers and other work providing agencies and the wider interests of the local community. (Ireland, Department of Education 1993, 5)

The guidelines advocate a whole school approach to TY planning and implementation.

\footnotetext{
${ }^{2}$ The Education Act (Government of Ireland 1998) describes educational disadvantage as 'the impediments to education arising from social or economic disadvantage which prevent students from deriving appropriate benefit from education in schools'. Since 2005, the DEIS programme, described as 'An opportunity for more effective service delivery to children and young people from disadvantaged communities' has offered targeted support to designated schools. See http://www.education.ie/robots/view.jsp?pcategory_10861\& language_EN\&category_402728\&link_link001\&doc_28202.
} 
Consultation with teachers, parents, students and community interests is proposed. The vision is that one of the teaching team should act as co-ordinator, assisted by a core team of four or five teachers drawn from distinct curricular areas (Ireland, Department of Education 1993, 11).

Thus, from a leadership perspective, having decided to offer a TY programme, numerous decisions then had to be made about the shape of the programme. Data from these six schools show how each school has, in effect, adapted the TY Guidelines to suit its own vision of what it sees as most appropriate for its students, as well as for the school as an institution with its own distinct ethos and culture. This may be seen as each school's domestication of TY. While the term 'domestication' means, literally, 'to make fond of home life', it is used here in the sense that schools adapt and shape TY to integrate it into their existing priorities and practices; they tend to emphasise those aspects of TY that 'fit' with their tradition and sense of identity. Furthermore, domestication also implies 'taming' and the evidence points to schools tending to downplay or even omit aspects of TY that are particularly challenging. This leads to a dilution of TY and opens the way for the programme to be colonised by values and practices associated with existing established programmes, notably the high stakes LC and its associated points system. Leaders, particularly principals and programme co-ordinators, play a key role in the extent to which the initiative is embraced or diluted. As Callan (2006) and Heywood (2008) argue, a curriculum leader's knowledge and value base is crucial for effective leadership.

\section{Benefits of TY}

There is strong evidence that TY is very effective in developing 'soft skills' (Smyth, Byrne, and Hannan 2004; Jeffers 2007). For example, teachers, students and their parents report very clearly that TY assists young people to become more confident, more mature, more socially skilled, and in many cases, better motivated. In schools where TY is optional, teachers report that it is young people who have done TY who dominate leadership positions during the final two years in school (Jeffers 2007, 232).

The evidence regarding academic development is more contested. On the one hand, longitudinal studies have shown that those who follow TY achieve significantly higher LC points that their counterparts who don't (Millar and Kelly 1999; Smyth, Byrne, and Hannan 2004). On the other, however, critics of TY will argue that it is not clear what role, if any, the personal and social development dimensions and other TY 'enrichment' activities play in this. They tend to favour a narrow, more academically focused curriculum.

From a leadership perspective, this presents two very distinct challenges. Firstly, how well can the more novel features of TY, especially the 'wide range of teaching/ learning methodologies and situations' (DES 1993, 8), be integrated with the traditional academic strands so that the result is a coherent educational experience? The evidence is strong that a cautious approach to curriculum design is taken perhaps a polite way of saying 'veering towards a three-year LC' ${ }^{3}$ - even when schools have extensive autonomy to be imaginative and creative. Less traditional

\footnotetext{
${ }^{3}$ The Transition Year Programme, Guidelines for Schools (DES 1993, 5) are exceptionally clear that: 'A Transition Year programme is NOT part of the Leaving Certificate programme, and should NOT be seen as an opportunity for spending three years rather than two studying Leaving Certificate material'.
} 
activities, especially ones suggested to promote personal and social development, take time to be valued. However, when their benefits start to emerge, they can spark a fresh enthusiasm. This was evident in Beech School, one of the two schools designated 'disadvantaged' in the study. For example, a co-ordinator remarks:

Introducing Transition Year fundamentally changed the relationship between the senior students and the teachers. Before that ... there was a lot of frustration, a lot of tension. Teachers were pushing and the kids were resisting ... I think the activities outside the classroom in Transition Year, hill-walking and other trips for example, are important in developing and improving teacher-pupil relationships.

This theme of the quality of student-teacher relationships emerged strongly from the student data and the parent data. A more diverse curriculum combining learning inside and outside the classroom, less focus on examination success, and more autonomy for individual teachers all contribute to warmer student - teacher relationships and a more positive disposition towards school on the part of students. The quality of student-teacher relationships is also identified as key in a recent study highlighting factors in school retention rates (Banks et al. 2010).

A second challenge for school leaders in relation to the balance between the personal and social development emphasis of TY and the academic strand relates to the key question: what will we tell the parents? Principals and co-ordinators often remark that once you show data highlighting the correlation between doing TY and increased LC points, most middle class parents come 'on board'. But the underlying thrust of TY is to counter-balance the effects of the 'academic treadmill'; it was meant, primarily, to be about personal development and community service (Burke 2001). Trying to convince parents, especially those who have limited school experience themselves, of the benefits of a programme that enhances 'soft skills' is rarely easy. Of course, if a school leader has 'sold' TY mainly on the basis of improving academic achievement, this almost inevitably leads to a narrowed curriculum and a shying away from TY's more radical inclinations. However, when the students respond well to a successful learning activity, their enthusiasm can spill over into the wider school community, including school leaders. When he was first interviewed, the principal of Oak School remarked:

They are just back from work experience and there is a great buzz around. You can see the difference when they come back from work experience $=$ the confidence they gained in mixing and dealing with adults for a fortnight. (Jeffers 2007, 211)

Potentially, a major benefit of the TY programme lies in the arena of teacher development. This potential is much more likely to be realised if teachers are given both the freedom and support to devise innovative programmes. When this occurs, the effect can be quite transformative. The co-ordinator in Maple School remarked: It's unbelievable the scope you have in TY. The difference is really in imagination, the imagination of the team of teachers involved. We are fortunate here that this is recognised. (Jeffers 2007, 194)

The principal of Oak School spoke about how TY can enable the building of capacity across the school and have a leavening effect beyond the particular initiative: 
I think it (TY) has helped develop a new pool of skills within the staff. It opens up teachers' minds to new ways of doing things. (Jeffers 2007, 226)

\section{Managing the micro-politics}

When interviewed, principals demonstrate a keen awareness of the rhetoric associated with TY. The six principals in this study voiced strong beliefs in the values that underpin TY: holistic education; the focus on personal and social development; active student engagement in learning; the possibilities of learning beyond the classroom; intrinsic rather than extrinsic motivation; school-based curriculum development; the possibilities of teacher creativity; and building bridges between schools and their local communities were all highlighted. Each was also keenly aware of the tensions between the aspirations of TYand the prevalence of a utilitarian view of schooling. TY is a clear example of the challenge for school leaders to bring coherence to a school's operation. It illustrates the point made by Fullan (2005) that not only is 'coherence making' one of five key components ${ }^{4}$ of leadership but 'learning to tolerate ambiguity' is a particular manifestation of this.

More bluntly, each principal also indicated that TY heightens an awareness of schools as sites of micro-political activity, where, as Ball notes, 'In no other institution are notions of hierarchy and equality, democracy and coercion forced to co-exist in the same close proximity' (Ball 1987, 15), and as Sarason says: 'Any educational reform that does not explicitly and courageously own up to issues surrounding changing patterns of power relationships is likely to fail' (Sarason 1996, 31).

In this way TY, as a major curriculum innovation, places the principal's own education values centre stage. As has been noted in other studies, the rest of the school community will often take their attitudinal cues from leaders. Evans, for example, asks, why should anyone take an initiative seriously if the leader doesn't? He also contends that:

Leaders who are followed are authentic; that is, they are distinguished not by their techniques or styles but by their integrity and their savvy. Integrity is a fundamental consistency between personal beliefs, organisational aims, and working behaviour.

(Evans 1996, 184)

Riley $(2008,167)$ makes a similar point in relation to wholeness, and Callan (2006) maps the links between living with ambiguity and the nurturing of professional relationships among staff. He notes that these relationships need to be nurtured and: ... must be capable of absorbing anxieties, tensions, uncertainties and misgivings that are naturally experienced by people when they confront change; they must provide resources of a material and psychological kind in the provision of guidance, critical appraisals, confirmations, and affirmations. ... We need, in a word, a professional community of learners in which it is acceptable to admit of uncertainty, to seek guidance, to express creative ideas, $t$ challenge other ideas, to be bold in one's contributions, and to push out th frontiers of acceptable behaviour. (Callan 2006, 130)

\footnotetext{
${ }^{4}$ The other four are: 'acting with moral purpose'; ‘understanding the change process'; 'relationship building'; and 'knowledge building'. He sees the five components united in the personal characteristic that he calls 'the energy-enthusiasm-hopefulness constellation'.
} 
In the context of TY, political considerations at local level, especially between neighbouring schools, can also come into play. There is widespread anecdotal evidence among teachers that many schools embarked on TY 'because other schools were doing it', rather than because of a well thought out rationale, or a particular commitment to education for personal and social development or to educational innovation. Thus, in some cases, programmes were assembled without as much discussion, analysis and focus as the official guidelines propose (DES 1993). Subsequently, some teachers found themselves teaching individual components of the programme with limited orientation and less resources. These forces often conspired to encourage a conservative, even survivalist approach to teaching TY.

Thus, a sensitivity to school context and local micro-politics is an important dimension of leadership and reflects a wider debate that sees curriculum itself as highly contested in the Irish context (Gleeson 2010), though this debate is not always audible.

\section{Communicating about the innovation}

So far, the evidence points to school leadership requiring clear understanding, beliefs and values rating to TY. Evidence of the beneficial effects of TY from within the particular school also seems important. Furthermore, an ability to manage the micropolitics associated with TY is an important leadership dimension. On top of all these, and to some extent integrating them, is a capacity for communicating in a coherent way, formally and informally, to students, parents, teachers and the wider public, how TY fits into the wider mission of the school. This centrality of communications is a development of what a range of commentators (see Leithwood, Jantzi, and Steinbach 1998; Sergiovanni 1996, 2001; Fullan 2001, 2005; Bennett, Crawford, and Cartwright 2003; Harris and Muijs 2005; Heywood 2008) variously call building visions, clarifying and articulating goals, and sense-making.

Each of the school leaders in this study demonstrated awareness, in varying degrees, of the importance of their role in explaining TY to stakeholders and linking it to the wider mission of the whole school. Furthermore, like many Irish school leaders, they recognised the daily struggle it can be to maintain a focus on 'learning'.

As the OECD country background report for Ireland noted:

Instructional leadership has been deemed to be the most neglected aspect of the principal's work in school. (OECD 2007, 41)

Some of the six principals recalled the memory of an earlier study which noted that principals generally involve themselves directly with 'low value' tasks and that 'many of these tasks are maintenance and janitorial in character' (Leader and Boldt 1994, 95). Engagement with such tasks has tended to relegate matters such as curriculum innovation further down a school's agenda. Indeed, it is not unknown for leaders who try to collaborate with teachers on curriculum related matters to find themselves rebuffed (Jeffers 2006). Perhaps significantly, the principals in this study were aware of this occupational tendency and keen to engage with the issues.

As already implied, there are subtleties and nuances associated with what exactly is being communicated to stakeholders. One example, from the information booklet for parents given in Maple School, indicates how layered this communication can be. The influence of the work of Howard Gardner is clear. What is also evident is a conscious effort by this school to move beyond the language of official policy documents. The booklet addressed parents directly: 
As teachers and parents we know that our students have many talents and skills. Unfortunately they do not always get an opportunity to develop these because in following both Junior and Leaving Cert. examinations students are tied to their academic work, often being spoon-fed by us teachers.

Transition Year changes that. Students get an opportunity to offload the confines of an exam-led curriculum - albeit for a year. In Transition Year they get the opportunity 'to do things for themselves' and 'to learn by doing'. They gain valuable 'hands-on' experience- often learning more from their mistakes and defeats. (Jeffers 2007, 198).

he booklet continues with a simplified outline of Gardner's (1984) theory of Multiple Intelligences and how TY in Maple School attempts to develop 'dormant' intelligences beyond the logical-mathematical and linguistic. The attempt is to connect with terms that parents are likely to recognise:

We strive to develop skills that will see them through well beyond their Leaving Cert - skills such as responsibility, initiative, time management and social skills. The extra year in school gives them that extra maturity to be ready for what life throws at them. It is not always while students are 'in' Transition Year that they reap the rewards. It is after they have moved on into the Senior Cycle and are far better able to cope with subject and career choices. (Jeffers 2007, 198)

From the activities undertaken by principals in relation to communicating with stakeholders about TY and linking them with suggestions from students, parents and teachers, it is possible to propose a more detailed framework that might have relevance to any curriculum initiative. The five-part framework is set out in Table 3. The importance of understanding, listening and talking should be clear from the earlier part of this article. The evidence from the study identified the TY co-ordinator as such a key player in the implementation of the programme, that some exploration of 'delegation' follows.

\section{Table 3. School leaders communicating to stakeholders about a curriculum initiative.}

Understanding

Listening

Talking

Delegating
The rationale

The main operational details

The likely impact on existing practice

To concerns of all stakeholders

For resistance and reasons for it

Ongoing - including evaluation

Dialogue with all stakeholders

Support for values of innovation

Promoting the innovation's potential

Reassuring the fearful

Real authority to team

Having faith in their abilities

Being open to feedback and hitches

Opportunities for team to report back 
Providing practical support Resources necessary to implement innovation

Time for teachers to meet and discuss

On-going, in-school teacher development

Dialogue with other schools re. the innovation

\section{Delegation and collaboration}

'Vital though the school principal is, school leadership does not begin and end with the person in the principal's office' (Spillane 2006, 5). In various studies, the programme co-ordinator emerges as central to successful implementation of TY programmes (TYCSS 2000; Smyth, Byrne, and Hannan 2004; Jeffers 2007).

Furthermore, close collaboration between principal and co-ordinator also seems crucially important.

Organisationally, Irish second-level schools are relatively undifferentiated. The majority of schools have student populations of between 300 and 800 students. A typical school with an enrolment of 500 students might have a teaching staff, fulltime and part-time, of between 30 and 40. Much day-to-day administration falls to the principal and deputy principal. There has been only a limited tradition of what is sometimes called 'middle management'; in many schools teachers carry teaching loads of 22 hours per week with relatively minor additional duties. Furthermore, appointment to a position of 'assistant principal' is, in the majority of schools, on the basis of seniority.5

Against this background, TY co-ordinators emerge with various identities, ranging from those with relatively senior positions within the existing hierarchy to young, often recently appointed teachers with a particular enthusiasm for TY. Personal commitment to TY emerges as a powerful factor. One study (TYCSS 2000) found that TY co-ordinators regard 'lack of time' as the biggest challenge they face. At the same time these co-ordinators reported high levels of job satisfaction, particularly derived from 'the student development enabled by the TY experience'. The data suggest that good co-ordination is central to the effective implementation of a TY programme. Teachers see 'the work done by the co-ordinator' as the single most important in-school factor contributing to the success of TY (Jeffers 2007, 255). Thus, while TY's ongoing vitality requires committed, competent and confident coordinators, in practice, a number of contentious issues can simmer below the surface of this assertion. The data support the view that schools are complex organisations (Aitken and Handy 1990) that are sites of contestation (Ball 1987) and where curriculum matters are constantly being reviewed and negotiated (Callan 2006; Gleeson 2010), and that TY is a prime focus for such debate, with principals and co ordinators often centre stage in the drama.

While the guidelines appear to recognise the heavy workload involved in coordination and that relying on a single co-ordinator is rarely sustainable, the evidence suggests that co-ordinators, especially when very committed and competent, can be left to operate without the support of core teams. The culture of autonomous yet isolated individuals remains strong. 
While co-ordinators were comfortable with co-ordination regarding students and parents, they are often more tentative in regard to colleagues. Cultural traditions that value autonomy and often rate length of service above particular competences can inhibit collegiality. While neither age nor gender necessarily restrict co-ordinators in their work, the micro-political culture of some schools may present them with additional challenges, especially if they are younger rather than older and female rather than male. Getting colleagues to be more open to active teaching methodologies, assessment techniques, student feedback, collegial planning, writing their modules and generally opening up the sacred space of their classrooms presents exacting challenges.

Evidence from students, parents, teachers and principals makes it very clear that the co-ordinators in this study were respected as both hardworking and committed. They were usually closely identified with TY and regarded as enthusiastic and effective advocates of the programme. While at one level the presence of an inspirational coordinator can be a great bonus for a school, Evans' warning about programme advocates is germane. He contends that having a strong commitment to an innovation, even having the authority to implement it, can prove counterproductive (Evans 1996, 16). Such commitment can generate impatience, and make one less amenable to modifications and less tolerant of delays.

Thus, a paradoxical finding in relation to TY is that, while the work done by individual co-ordinators is seen as vital for the programme's development, there is also a strong sense in some of the six schools that without these particular coordinators, the programme might, if not quite crumble, be significantly weakened. Hence, the wisdom of developing a whole school approach to TY, or at least the extending from individual co-ordinators to co-ordination teams, appears endorsed.

Particular characteristics emerge as desirable in the relationship between principal and the programme co-ordinator of an innovation. A strong belief in the worth of the project appears to be essential in the co-ordinator and most desirable in the principal. Secondly, in a hierarchical structure like a school there has to be real delegation and trust from principal to co-ordinator. This usually manifests itself with the handing over of specific responsibilities, including some financial, curricular and day-to-day decision-making. While some channel of formal accountability from coordinator to principal is desirable, occasional displays of genuine interest in the innovation's progress by the principal appear to consolidate the working relationship. Principals need to strike a delicate balance between control and autonomy, maintaining support without intrusion.

Within the delegation and collaboration context, the development of coordination teams and genuine cross-curricular teamwork seem to present a particular challenge as there is little evidence of such practice. A strong culture of teacher individualism and isolation within schools, sometimes masquerading as autonomy, appears to play a strong role in inhibiting collegial development. In this context, TY could benefit from the model of ‘autonomous distribution' of leadership presented by Harris $(2008,122)$.

\section{Effecting change}

Therefore, the evidence from TY regarding leadership points towards five interlinked factors at play in implementing this example of educational change with a 'leading 
learning' focus. They are:

- The principal's own beliefs about the underlying values of the innovation are important.

- Evidence of real tangible benefits of the progamme is important as is the ability to live with tensions and even contradictions.

- Communicating the values associated with TY, especially those that might be in tension with the currently dominant values in a school, requires delicate conversations with staffroom colleagues, with parents and with students and should be directed towards 'coherence making' .

- The school context and political environments are vital considerations that impact on the consolidation of the initiative and deserve close attention. These contexts include both the school as an distinct entity and also local clusters of schools.

- An innovation as extensive as TY requires delegation of real responsibility to a programme co-ordination, but is best achieved in a way that is supportive and does not appear like off-loading.

The OECD (Pont, Nusche, and Moorman 2008) identified four main policy levers which, taken together, can improve school leadership practice. They are set out in Table 4.

Table 4. Policy levers to improve school leadership practice (Pont, Nusche, and Moorman 2008).

\begin{tabular}{|c|c|c|}
\hline $\begin{array}{l}\text { (1) }(\mathrm{Re}) \text { define school } \\
\text { leadership } \\
\text { responsibilities }\end{array}$ & $\begin{array}{l}\text { Provide higher degrees of } \\
\text { autonomy with appropriate } \\
\text { support (linked with new } \\
\text { models of distributed } \\
\text { leadership, accountability } \\
\text { and training and } \\
\text { development) } \\
\text { Redefine school leadership } \\
\text { responsibilities for } \\
\text { improved student learning } \\
\text { Develop school leadership } \\
\text { frameworks for improved } \\
\text { policy and practice }\end{array}$ & $\begin{array}{l}\text { Supporting, evaluating and } \\
\text { developing teacher quality. } \\
\text { Goal-setting, assessment } \\
\text { and accountability. } \\
\text { Strategic financial and } \\
\text { human resource } \\
\text { management. } \\
\text { Collaborating with other } \\
\text { schools. } \\
\text { Recruitment, training and } \\
\text { appraisal of school leaders } \\
\text { should be on the basis of } \\
\text { 'leadership for learning' as } \\
\text { the essential characteristic } \\
\text { of school leadership }\end{array}$ \\
\hline $\begin{array}{l}\text { (2) Distribute school } \\
\text { leadership }\end{array}$ & $\begin{array}{l}\text { Encourage distribution of } \\
\text { leadership } \\
\text { Support distribution of } \\
\text { leadership } \\
\text { Support school boards in } \\
\text { their tasks }\end{array}$ & \\
\hline $\begin{array}{l}\text { (3) Develop skills for } \\
\text { effective school leadership }\end{array}$ & $\begin{array}{l}\text { Treat leadership } \\
\text { development as a } \\
\text { continuum } \\
\text { Ensure consistency of } \\
\text { provision by different }\end{array}$ & $\begin{array}{l}\text { Encourage initial } \\
\text { leadership training. } \\
\text { Organise induction } \\
\text { programmes. } \\
\text { Ensure in-service training }\end{array}$ \\
\hline
\end{tabular}




\begin{tabular}{|l|l|l|}
\hline & $\begin{array}{l}\text { institutions } \\
\text { Ensure appropriate variety } \\
\text { for effective training }\end{array}$ & to cover need and context. \\
\hline $\begin{array}{l}\text { (4) Make school leadership } \\
\text { an attractive profession }\end{array}$ & $\begin{array}{l}\text { Professionalise recruitment } \\
\text { Focus on the relative } \\
\text { attractiveness of school } \\
\text { leaders' salaries } \\
\text { Acknowledge the role of } \\
\text { professional organisations } \\
\text { of school leaders } \\
\text { Provide options and } \\
\text { support for career } \\
\text { development }\end{array}$ & \\
\hline
\end{tabular}

A detailed examination of this framework is not possible here. However, using it as a lens to examine the TY experience as illuminated through six schools and also reversing the process to critique the OECD framework, a number of points are worth noting:

(1) Highlighting 'leadership for learning' (Pont, Nusche, and Moorman 2008, 9) as the essential characteristic of school leadership is welcome but the evidence from this study is that such leadership needs to be grounded in a close familiarity with, and strong belief in, the programme and curricula being offered by a school. This is especially true in relation to curriculum innovations. This need to focus on educators' core values and beliefs also has implications for 'leadership programmes' (ibid., 125) and how the profession is profiled (ibid., 111).

(2) Actively communicating about a school's mission and about 'learning' emerges as a core leadership activity in developing TY in a school. The leader as the articulator of vision and values appears underplayed in the OECD framework.

(3) The domestication of TY by individual schools is a key finding in the study. In essence, this points to the relevance of individual school contexts. Schools adjust, adapt and ignore aspects of policy in accordance with their own sense of identity. Thus 'autonomy' can be a two edged sword and may even be invoked to support the status quo and resist change. Respect for context also suggests that while a broad OECD-wide framework has its uses, manifestations, opportunities and challenges are likely to vary from country to country.

(4) Experience from TY suggests that programme co-ordination and greater teacher autonomy illustrate the value of distributed leadership. An important caveat from this study is how easily delegation can be seen as 'off-loading'.

(5) 'Coherence-making' and reconciling tensions- notably in the case of TY and the established LC- is a difficult task. In this complex framework, there are potential tensions between the emphasis on 'autonomy' (for leaders) and greater accountability and 'human resource management'. The evidence from the TY experience is that 
greater teacher autonomy can, with support, enhance teacher professional development. In the context of school leadership, trust may be a value that is in danger of being eroded due to overregulation and management. As has been noted:

'Giving teachers the opportunity to lead and take responsibility for the areas of change most important to the school . . . this form of leadership necessarily requires relinquishing the idea of structure as control and viewing structure as a vehicle for empowering others' (Harris and Muijs 2005, 14).

(6) Individual school contexts emerge from the TY study as highly significant, as do the leadership styles of individual principals. The principals in this study tend to veer towards what Fullan $(2001,7)$ calls the 'energyenthusiasm- hopefulness constellation'; the possibility of change often wins out over any resignation to mediocrity. Individual personality and flair appear to be important qualities in school leaders.

(7) The TY experience throws a particular shadow over the admirable aspiration of collaboration with other schools. In practice, in the schools in question, resistance to collaboration manifested itself in complex ways. There is a constant awareness of the policies and practices regarding TY in neighbouring schools as schools are often in competition with each other for students, and by extension, for teaching posts. The phenomenon of domestication, discussed earlier, arises partly from this competitive context. For example, if in a particular town the school perceived to be more 'academic' is offering a 'cautious' programme, this is seen- particularly by those in the two designated 'disadvantaged' schools, Oak and Beech -as having an inhibiting effect on their neighbours. Sharing ideas, materials and insights, particularly about 'failures', is difficult in competitive environments. Indeed, in a competitive environment, it appears that apparent collaboration can promote mediocrity.

\section{Conclusion}

The TY experience is a particularly relevant illustration of a curriculum initiative that, for successful implementation, required a strong leadership for learning focus. The evidence points to a complex inter-relationship of factors at work including: the principal's own beliefs and values about the initiative; the gathering of reliable evidence of the benefits of the programme; an ability to manage the micro-politics of the situation; the communication strategies employed with stakeholders; and the style of delegation and support offered to programme co-ordinators and teaching staff. Articulating a coherent view of TY emerges as a key role for school leaders. This includes listening to the concerns of all stakeholders, clarifying how the values of TY support and challenge the stated and unstated values of the school, encouraging a climate that respects innovation and using time in ways that prioritise learning. In particular, it involves a capacity to dialogue and to delegate - particularly to coordination teams- and play a lead role in telling the school's TY story with a voice that is authentic and consistent with their own values, both spoken and practised. Much of the evidence concerning leadership of TY resonates with the OECD (Pont, Nusche, and Moorman 2008) policy framework for improving leadership practice. The TY experience also points to some possible adjustments and additions to, as well as some re-focusing of, that framework.

\section{Acknowledgements}


An earlier version of this paper was presented at the American Educational Research Association (AERA) Annual Meeting in San Diego, 2008. The author is especially grateful to the insightful and constructive comments from two anonymous referees.

\section{Notes on contributor}

Gerry Jeffers is a lecturer in education (Innovation and Development in Schools) at the Education Department, National University of Ireland, Maynooth, Co. Kildare, Ireland.

\section{References}

Aitken, R., and C. Handy. 1990. Schools as organisations. London: Penguin.

Ball, S.J. 1987. The micro-politics of the school: Towards a theory of school organisation. London: Methuen.

Banks, J., D. Byrne, S. McCoy, and E. Smyth. 2010. Engaging young people? Student experiences of the Leaving Certificate Applied Programme. Dublin: NCCA, ESRI.

Bennett, N., M. Crawford, and M. Cartwright, eds. 2003. Effective educational leadership. London: Paul Chapman.

Callan, J. 2006. Developing schools, enriching learning: The SCD experience. Maynooth: NUI Maynooth Education Department.

Evans, R. 1996. The human side of school change _ reform, resistance and the reallife problems of innovation. San Francisco, CA: Jossey-Bass.

Fullan, M. 2001. Leading in a culture of change. San Francisco, CA: Jossey-Bass.

Fullan, M. 2005. Education in motion, leading in a culture of change. Paper presented on UK and Ireland Workshop Tour, May 2005. Available from: http//www.michaelfullan.ca.

Gardner, H. 1984. Frames of mind. New York: Basic Books.

Gleeson, J. 2010. Curriculum in context _ partnership, power and praxis in Ireland. Oxford: Peter Lang.

Harris, A. 2008. Distributed school leadership _ developing tomorrow's leaders. London: Routledge.

Harris, A., and D. Muijs. 2005. Improving schools through teacher leadership. Buckingham: Open University Press.

Heywood, J. 2008. Instructional and curriculum leadership _ towards inquiry oriented schools. Dublin: National Association of Principals and Deputies.

Ireland, Department of Education. 1993. Transition Year Programme, guidelines for schools. Dublin: Department of Education.

Ireland, Department of Education and Science. 2004. A brief description of the Irish education system. Dublin: Department of Education and Science.

Jeffers, G. 2006. Conversations on teaching and learning: A challenge for school leadership. Oideas, Journal of the Department of Education and Science 52: 25_40.

Jeffers, G. 2007. Attitudes to Transition Year: A report to the Department of Education and Science. Maynooth: Education Department NUIM.

Leader, D., and S. Boldt. 1994. Principals and principalship, a study of principals in voluntary secondary schools. Dublin: Marino Institute of Education.

Leithwood, K., D. Jantzi, and R. Steinbach. 1998. Changing leadership for changing times Buckingham: Open University Press. 
Millar, D., and D. Kelly. 1999. From Junior to Leaving Certificate: A longitudinal study of 1994 Junior Certificate Candidates who took the Leaving Certificate examination in 1997, final report. Dublin: ERC/NCCA.

OECD. 2007. Improving School Leadership _ country background report_ Ireland. Ennis: Leadership Development for Schools (LDS), Department of Education and Science, and OECD.

Pont, B., D. Nusche, and H. Moorman. 2008. Improving school leadership volume 1: Policy and practice. Paris: OECD, Directorate of Education.

Riley, K.A. 2008. Improving city schools:Who and what makes the difference? In The future of educational change, ed. C. Sugrue, 155_71. London: Routledge.

Sarason, S.B. 1996. Revisiting 'The culture of the school and the problem of change'. New York: Teachers College Press.

Sergiovanni, T.J. 1996. Leadership for the schoolhouse. San Francisco, CA: Jossey Bass.

Sergiovanni, T.J. 2001. Leadership: What's in it for schools? London: RoutledgeFalmer.

Smyth, E., D. Byrne, and C. Hannan. 2004. The Transition Year Programme: An assessment. Dublin: Economic and Social Research Institute and Liffey Press.

Spillane, J. 2006. Distributed leadership. San Francisco, CA: Jossey-Bass.

Stoll, L., and D. Fink. 1995. Changing our schools. Buckingham: Open University Press.

Sugrue, C., ed. 2008. The future of educational change. London: Routledge.

TYCSS (Transition Year Curriculum Support Service). 2000. Transition year survey on coordination: Report on findings. Du'n Laoghaire: Blackrock Education Centre, TYCSS. 